\title{
Matter Out of Place: Migrating Modernity and Unauthorised Archives
}

lain Chambers

\section{(2) OpenEdition Journals}

Electronic version

URL: http://journals.openedition.org/transtexts/726

DOI: $10.4000 /$ transtexts. 726

ISSN: 2105-2549

Publisher

Gregory B. Lee

Electronic reference

lain Chambers, "Matter Out of Place: Migrating Modernity and Unauthorised Archives », Transtext(e)s Transcultures 跨文本跨文化 [Online], 12 | 2017, Online since 24 October 2018, connection on 19 April 2019. URL : http://journals.openedition.org/transtexts/726 ; DOI : 10.4000/transtexts.726

This text was automatically generated on 19 April 2019

(C) Tous droits réservés 


\title{
Matter Out of Place: Migrating Modernity and Unauthorised Archives
}

\author{
lain Chambers
}

1 Matter out of place is what historians would call an anachronism, and anthropologists a taboo. In a more prosaic language it is what everyday racial thinking and practices identify as the disturbance of a supposedly preordained social and cultural order. In the following pages I wish to explore how these apparently separate realms are actually stitched into a shared political and cultural register. This leads us to understand how specialised abstract languages and institutional knowledge contribute, notwithstanding their 'distance' and scientific status, to the configurative flows of daily definitions and sense. I wish to suggest that the analytical languages we deploy and the paradigms that anchor their valency may also be part of the problem, blocking a richer and more complicated series of understandings. The refusal to dig deeper into the Occidental archive, dirtying its premises and crossing its particular temporality with contemporary concerns - anachronisms - in the end becomes the refusal to take critical responsibility for the present.

2 Let us start simply from the question of considering theory and critical thinking as a device of power. For we are dealing with an assemblage of knowledge and practices that historically participated directly and indirectly in the hierarchisation and consequent racialisation of the planet, via the violent imposition of Western capital in its management of planetary resources. Thinking about the current historical moment and the explicit return of a white supremacist ideology, from the framing of the modern immigrant as illegal to Brexit and the politics of Donald Trump, it becomes more and more urgent to adopt a critical approach capable of radically re-evaluating not only one's own culture, but also the critical tools - even in their most radical variations - that have supported the assumptions and languages of racial power.

3 Further, in the increasing return to racial distinctions and cultural defence by the organs of government and their press, we today find ourselves propelled into the abyss of the 
colonial archive. We are increasingly confronted not simply with a history that refuses to pass (racism and the subjugation of the rest of the world to our needs), but also with the explicit colonial constitution of the present in which capitalism, colonialism and modernity become one. Where an earlier liberal order could pretend to insist on the distinctions and point to a progress that would eventually slough off the terrible accretions of an earlier stage in the Occidental framing of the world, today we are forced to acknowledged the bottom line of a 'global colonial archive' that continues to promote the syntax of the present. ${ }^{1}$ We have not, and cannot, reason our way out of the formula that reveals capitalist modernity as colonialism without adopting a more radical cut and critique. The continuous necessity of capital to expand its circuits of production, reproduction, consumption and extraction through reducing all of nature and technology to its standing reserve, accepts no limits. The breakdown of a planetary order is inevitable as it fractures into increasingly limited access to resources and riches. Of course, if we are unwilling to seek salvation in a deity, we can drily conclude that the story of humanity is simply a blink in the time scale of the universe. But to live this situation as a challenge, rather than a destiny, what is the solution? Perhaps there is none precisely to degree that we continue to think and practice our activities in a manner of thinking that remains subservient to a teleology of time. After all, today considering our planetary framing was the earlier moment of Occidental liberalism, despite an explicit appeal to humanism and Christian morality, any less vicious, brutal and cruel?

implies adopting a very different understanding of time - both as memory and history. It is means to insist, against the prevailing premises of historiography, that it is precisely the anachronistic, matter out of place disturbing its designated location in a linear and progressive temporality, that inaugurates a necessary analytical cut and the inauguration of a diverse critical configuration.

5 If we were to take seriously, for example, the critical voices that come from the margins of yesterday's colonial world, from the Caribbean of Aimé Césaire, CLR James, Frantz Fanon, Edouard Glissant, Derek Walcott and Stuart Hall (black Jacobins whose masculinity also lead to further discussion), and insert them into the canon of Western philosophy, their very presence, once acknowledged, undermines the premises and protocols of philosophy itself. The parable that begins on the Mediterranean shore (although we know that the Western logos commenced in the Greek colonies in Asia, with a major debt to the Persian and Egyptian world), and arrives in today's university departments would have to be interrupted and rethought in altogether more worldly terms, and not exclusively European. Here we need only recall the famous verdict of Frantz Fanon in The Damned of the Earth, where a European humanism continually massacres human beings in every corner of the globe in order to affirm itself as a universal measure.

6 It would also be significant to trace a distinction between the disciplined concept of history, as an institutional practice of narrating and explaining the past, and the more unruly evidence that arrives from archives read against the grain, held up to the light to expose their colonial formation, and registered as practices that both display and discriminate, collect and censure. While history apparently takes care of the past, registering and affirming its truth, the turbulent archive, posing questions of ownership and authority, promotes a more extensive critical space composed in practices and powers that are always contested and under construction. Here the past, not yet fully defined, recognised nor interpreted, must still arrive from the future. This distinction frees the archive from the disciplined domain of the historiographical apparatus. The 
materials and the lives that constitute an archive exceed any chronological narrative pushing towards the coherence that a stabilised history seeks to impose. The discrete, the singular and the exception, in combination and in discontinuity, sting and punctuate the linear assumptions of time, through deepening, multiplying and dispersing it. Moreover, the tools of the story - its languages and its prose (and therefore its poetics, both ugly and beautiful) - are themselves also governed by the boundaries of the spatial temporality in which they are elaborated. It is still a limited, confined, historical act.

Insisting on the idea of culture as a mobile configuration of social practices, irreducible to the stability of an object or an isolated text, means grasping the historical complexity of its formation precisely through insisting that its premises are also historical. This, too, turns out to be a historical challenge: rendering cultural definitions and verdicts currently in vogue foreign to themselves; in other words, exposing them to questions they have not authorised. If this is a methodology - but of course this term, like that of historical 'facts' and the social 'sciences' is, in turn, still to be elaborated and defined - it's premises lie in unstable and fluctuating procedures, which, being historically situated, cannot be established once and for all.

8 At this point, through transforming what has been inherited and understood as normative, both in everyday life and in specialised knowledge practices, we find ourselves close to the cut proposed by Michel Foucault. In Foucault definition, 'science' is not in compliance with the rules of disciplinary protocols, as these tend merely to reconfirm the starting point of the research. On the contrary, science lies in the cut that establishes a discontinuity capable of dismantling and reassembling the rules of a previous disciplinary discourse. ${ }^{2}$ Once shattered, and therefore made vulnerable to other horizons and other questions, it is possible to promote traversal paths across the existing settlement of the social sciences and their domestication of the world.

The price of the critical refusal to face such questions is central to the failure of historiography that leads to the victory of historicism. Here is the difference, for example, between 'gender history', practiced almost always and exclusively as an extension of the historiographical apparatus, thereby adding a further element to the inherited picture (as happened when feminist critique was translated into 'women's history'), and the requirement 'to queer' that history, cross the confine and confute the power of that knowledge apparatus.

10 At this point two intertwined trajectories emerge. One is related to a positioning in the existing fields of knowledge and their disciplinary protocols. Foucault famously explored the historical and epistemological elaboration of these fields and their modern transformation into autonomous disciplines. The other dimension, which in my opinion was less explored by Foucault, is that of the prospect of trans-disciplinary studies that propel us to evaluate not only the limits of modern knowledge revealed in European and Occidental practices, but also to register the structural removal of the rest of the planet from the equation, basically reduced to an inert object that reconfirms the centrality of our subjectivity. Here the other becomes part of history, of the social sciences, of the juridical system and of philosophy, only after being recognised and registered, after struggling through the brutal passage from the state of an anthropological object to becoming a historical subject. This passage - accentuated and accelerated in the present historical moment - puts in serious difficulty the disciplinary parameters (anthropological, sociological, historical, philosophical, juridical) that until now have made the world exclusively the object of our knowledge. 
11 All of this suggests that the violence of historical linearity needs to be diverted, subverted, torn apart. The anachronistic, that is historiography as a contemporary practice and configuration, must be acknowledged as a critical device. Discontinuity is practiced to interrupt the history that subjects us. In the bending of space-time, objects, stories and lives, once physically and temporally detached, are rendered proximate. Such folds in time record the depths of the stratified and complicated present, and its debt to a blocked and unacknowledged past. The refusal to elaborate this unruly past and recognise its place in the meaning and making of the present can only nourish a melancholic stasis, as Paul Gilroy so well explains in After Empire. ${ }^{3}$ The past continues to question us, interrogating our denial, rendering our knowledge and lives vulnerable to those unsuspected questions not authorised by the current languages and logics of the disciplines. Or, to use the words of the Caribbean poet Derek Walcott, "I met History once, but he ain't recognize me."4

Such a friction between recognition and removal disseminates a doubling of the historical archive, exposing its duplicity with an existing order. Against the unilateral setting of the history of Europe and its particular worlding of the world, other histories suspended in water, in the islands and in the planetary processes supported by the maritime traffic of bodies and ideas, continue to erode the claims of the West as the sole guarantor of the globe. It is not necessary to travel far to touch the vitality and violence of the question. Remaining within the national borders of a European country we can find ourselves 200 kilometres south of the cities of Tunis and Algeria on the island of Lampedusa. Here in southern Italy, in Europe, in the so-called First World, geographical distance is cancelled by a dramatic political and cultural immediacy. Following the suggestion of the Lebanese artist Akram Zaatari we can consider this particular landscape an archive. Among shipwrecked and illegal migrants, fishermen and government officials, tourists and owners of shops and restaurants, this is an area of volatile contact, in which the south of the planet impacts, often fatally, against the (over) developed world.

At this point, we can insist on the accumulated memories of migration that make up the Mediterranean. Yesterday, there were not only the poor of the peripheries of rural Europe who departed for the Americas, but also those who travelled to other colonial spaces in North Africa. At the beginning of the Twentieth century more than one million Europeans - largely French, but also with sizeable Spanish and Italian communities - lived in Algeria, while in Tunisia there were at least 100,000 Italians. In Libya in the 1930s some $13 \%$ of the population was made up of Italians. Today, the Mediterranean is traversed in the opposite direction by those coming from Africa and Asia looking for a better life. Today, the multiple south of the planet infiltrate the modernity that seeks to consign their histories to silence, transforming certain human beings into 'illegal' objects of our jurisdiction. If the current Mediterranean cemetery is witness to the necropolitics (Achille Mbembe) of global capital and its management of migrant flows, it is also the place where the limits of a European humanism and its historical order are registered. ${ }^{5}$ Although an illusory universal value it continues to subordinate the needs of the rest of the planet to its political and cultural will, allowing to sink beneath the waves, delivered to the abyss between the law and justice.

In the montage of intersecting temporalities and territories that come together in considering migration, modernity and the Mediterranean we need to remember that contemporary Mediterranean crossings constitute only a moderate percentage of the socalled illegal immigration into present-day Italy. Increasingly it is composed of refugees 
fleeing the killing fields of Syria, Afghanistan and sub-Saharan Africa (particularly Eritrea and Somalia). Most of the migrants, particularly those fleeing war zones, do not arrive in Europe at all. The biggest concentration of such displaced persons are to be found in Pakistan, Iran, Jordan, Lebanon, Kenya and Turkey. ${ }^{6}$ European media and political attention is of course fuelled by the drama of the escalating figures of drownings and death at sea. Behind these representations there exists another narrative that is rather less about the contemporary and planetary significance of modern migration, and altogether more to do with the construction and defence of local, national, European and Occidental framings of the world. So, what does present-day migration say about our understanding of modernity and ourselves? To answer this suggests that we think not so much of migration as with migration, as the latter becomes a critical instrument and interrogation. This leads into a deeper and altogether more extensive history of our time. The contemporary figure of the migrant and refugee does not simply represent a juridical and socio-economical figure, often destitute and temporarily stateless. She carries within herself a series of historical and cultural interrogations that invest modern forms of belonging: from the nation state and citizenship to what we understand when we speak of democracy and rights. These are questions sustained within a modernity that seemingly awards the mobility of capital, labour and production, and therefore inevitably, even if it is ideologically reluctant to do so, the migration of bodies, histories and cultures...

Inscribed on the body of the modern migrant is not simply the power of European law regulating her situation, and frequently transforming her subjectivity into an 'illegal' objectivity, but also the indelible watermark of a colonial past. Here the altogether more preponderant, systematic and violent migration of Europeans towards the rest of the planet in the course of several centuries, invariably forgotten and repressed, is re-ignited in the clandestine histories of today's migrants who return to shadow the complex coordinates of the modern world. Here we confront the intricate making of a constellation called modernity in which the past does not simply pass. Here, migration as a central element in the making of the West renders unstable, even unsustainable, the linear explanation that would consign the colonial migrations of Europe - realised through the racial and racist subordination of the rest of the world to its economical, political, religious and cultural will - to a closed and obsolete chapter in the narrative of its 'progress'. To re-open these histories, allowing them to spill into the present, means to propose profound interrogations of the historical and political nature of the modern nation state, its modalities of democracy and government, and the pretensions of its juridical premises and practices. For migrant bodies, invariably considered 'out of place', put in question the very sense of location and belonging upon which these definitions depend: in the ongoing processes of globalisation who has the right to define and direct this 'place'?

To consider contemporary migration, and the racism that invariably accompanies it, as being woven into the web of Western democracy, is to consider far more than a set of emergencies. With death spilling out of the headlines - from drownings in the Mediterranean to shootings in America's inner cities and the violent surveillance of territories and lives in Palestine - the limits and hypocrisies of the moral economy of the Occident are continually exposed. These are the limits of a precise history and its structures of power. They speak of the critical and political responsibilities for those processes that have brought us to where we are today. This means to understand the present movement of migration from the multiple souths of the planet, or the 
consistency of racism, as a historical condition, not simply as an 'emergency' that require exceptional measures.

For these are not temporary phenomena or accidental pathologies; they are structured, historical processes. If such processes are hidden behind the fetish of global commodification they nevertheless consistently ghost the making of the modern world. The spectral presence of invisible lives and anonymous labour in the global logistics of capital is both there in yesterday's slave ships plying the Atlantic and in today's overcrowded boats crossing the Mediterranean. Insisting that such questions are central, and not peripheral, brings us to confront the very mechanisms of knowledge and power that legitimate the present state of affairs. The presumptions that surround and sustain such concepts as the 'individual', 'citizenship', 'democracy' and 'freedom' are themselves the products of such mechanisms. While they continue to be presented as neutral ideals and universal values, their practices tell us a very different story. Precisely here, the figure of the migrant exposes the present to unauthorised questions and opens up another archive. This produces a radically diverse critical horizon.

What is repressed in the representation points us to other maps and temporalities in a planetary modernity that is never merely 'ours' to define. If the politics of explaining and managing the modern world can only be sustained though maintaining unequal relations of power and the negation of other voices and histories, then we should ask ourselves in what precisely does this universality and its modernity consist of? All of this implies extracting the discussion and understanding of contemporary migrations from its more predictable coordinates. This means to insist, against prevailing representations, that migration is neither merely a marginal socio-economical phenomenon nor a social 'problem' or political 'emergency'. On the contrary, migration is one of the constitutive processes in the making of modernity, both in its Occidental inception and its subsequent planetary realisation. The centrality, and not marginalisation, of migration to the making of the modern world was already passionately argued for more than 40 years ago by John Berger in A Seventh Man. ${ }^{7}$

As a structural and historical condition, intrinsic to the political economy and violent cartographies of the modern world, migration is a cultural, historical and epistemological challenge. The modern migrant with her history, culture and life actively questions the citizenship, national belonging and understandings of the European polity precisely to the degree that she invites us to consider their colonial fashioning and postcolonial configurations. Such considerations open up deeper historical temporalities and altogether more extensive and unstable archives than those associated with the homogenous time of national belonging. Clearly all of this cuts into and interrogates our very understanding of the present, forcing us to register the limits of a certain European and Occidental exercise of modernity.

21 At this point, and thinking with migration, we can begin to elaborate a different critical key with which to open and interpret the archives of modernity. This is an invitation to consider the rhythms and configurations that resist and persist in the folds of a deeper historical time. Here migration turns out to be the very motor of modernity itself. Given that the West insists on globalisation and its necessary worlding of the world then points of origin and ownership begin to evaporate. Or, rather, there opens up an epoch characterised by the explicit struggle for its definition and management. All of this suggests the necessity of adopting a diverse critical compass with which to navigate these emerging questions. Giving attention to subordinated, subaltern and subjugated 
memories we confront a politics and poetics that exceeds our reasoning and the presumption that we are always able to render the world transparent to our premises, needs, knowledge and power.

In this context it becomes pertinent to propose certain contemporary art practices in terms of a critical activity. Involving historical and cultural research, secured in an incisive postcolonial re-narration of modernity, this art deliberately pursues a significant political mandate and proposes a postcolonial turn within contemporary art. Challenging the existing geography of powers it leads to the dissemination of a semantics, with its sentiments and affects, that escapes the mechanisms of institutional narration to propose other affective understandings, other maps of knowing, other ways of seeing. With this in mind it becomes possible to repeat the dominant narration of the nation and belonging to its polity in an altogether more critical key. The radical revaluation, sustained by migration, exposes the institutional tale to those histories and cultures that have been structurally excluded and negated, reduced exclusively to objects of our knowing gaze. The exhibition of our 'progress' and the power of our modernity to reduce the world to a series of objects that reconfirm the centrality of our subjectivity - continually on display in national museums and history text books - is now intercepted by a series of unauthorised questions that persist and resist. These critical prospects, precisely because they are still largely unregistered and unrecognised, constitute a postcolonial archives destined to arrive from the future.

Here in the intersection of broken territories and interrupted narratives, the Mediterranean itself proposes a seascape that is both a liquid archive and a laboratory of modernity. How do can we traverse this space and its associated temporalities? To cross and conceive them requires the dis-assembling of a belonging guaranteed in a fixed, stable and rooted identity. We are pushed into a journey in a mobile geography, composed of movement, slippages and interruptions: both space and time become discontinuous, cut up by the heterogeneity of conflicting forces and desires. Moving between the representations of such spaces and the repression that shadows the act of being represented we find in postcolonial art an unsuspected anthropology, history and sociology of the present. Clearly, such art does not provide us with a stable object to analyse and explain according to the abstract logic of artistic canons - the institution of aesthetics, the history of art - but rather proposes a critical means with which to live and interrogate the discursive order - aesthetics, art history - that simultaneously constructs and explains the art object.

24 In this situation the past, with its memories and archives, proposes a diverse archaeology and a different manner of comprehending its presence in the present. The isolated and authentic object no longer exists, nor does a definitive explanation of the past. In the counter-histories and counter-memories that inhabit the image we can now register that the image itself contains more time and horizons of meaning that any one of us can ever absorb or understand. ${ }^{8}$ Here we pass from a formal archaeology of objects to an ongoing genealogy composed in relations, ruptures and discontinuities, where the past works up new critical configurations of the present. For what counts is not so much an object discovered as the processes exposed in the excavation.

The frontiers, borders and confines registered in steel walls, barbed wire, documents and bureaucracy, produce a wound, a scar that will never heal and is destined to remain open as an interrogation. Here we also touch the epistemological limits of an idea of citizenship and belonging articulated exclusively in the terms of the nation state which, and not by 
chance, is also the privileged place holder of modern historiography. Postcolonial art - in its literatures, visual arts and poetics - narrates a very different critical landscape. The echoes and spectres sustained in these works cut up time and refuse the simple linearity of 'progress' and the unilateral beat of the Occident. Here we find ourselves insisting, in the wake of Walter Benjamin, that historical time does not pass but rather accumulates. The past insists in the present in the form of ruins. Our silence in their presence is a hole in time. Here there emerge other histories and other lives, the others. The dissolution of institutional time into multiple rhythms and accents sustains critical spaces that lie at our side: frequently unregistered and unrecognised. These are the heterotopias that a postcolonial art practices and promises. ${ }^{9}$ They propose a folding of time, its simultaneous deepening and extension to render proximate other places and bodies in a cartography that exceeds the more predictable maps of modernity. Here, in the interruption and discontinuity of a uniform temporality and space, the syntax of art announces a world yet to come.

\section{NOTES}

1. Carmine Conelli, 'Challenging the Domestic Colonial Archive: Notes on the Racialization of the Italian Mezzogiorno' in Lars Jensen, Julia Suárez-Krabbe, Christian Groes, and Zoran Lee Pecic (eds.), Postcolonial Europe. Comparative Reflections after the Empires, London and New York, Rowman and Littlefield International, 2017.

2. Michel Foucault, "Nietzsche, Genealogy, History" in Michel Foucault, Language, CounterMemory, Practice: Selected Essays and Interviews, Ithaca, Cornell University Press, 1977.

3. Paul Gilroy, After Empire. Melancholia or Convivial Culture?, London and New York, Routledge, 2004.

4. Derek Walcott, 'The Schooner "Flight”', in Collected Poems, London, Faber \& Faber, 1992.

5. Achille Mbembe, On the Postcolony, Berkeley, University of California Press, 2001.

6. UNHCR figures for mid-2013, reported in The Guardian, 10 June 2014. If the figures are now clearly out of date the tendencies remain in place.

7. John Berger and Jean Mohr, A Seventh Man London, Verso, 2010 [1975].

8. Georges Didi-Huberman, Devant le temps. Histoires de l'art et anachronisme des images, Paris, Éditions de Minuit, 2000.

9. Michel Foucault, “Of Other Spaces”, Diacritics 16, n¹, 1986.

\section{ABSTRACTS}

This article seeks to unwind a series of premises that corroborate the premises of social sciences, arguing that their implicit role in the formation of modernity structurally renders their claims of 
neutrality and scientific questionable. Through considerations of contemporary migration and postcolonial art, the essay seeks to demonstrate the need for more flexible and provisional critical languages that, aware of their own historicity, are able to challenge the unilateralism of Occidental historicism.

\section{AUTHOR}

\section{IAIN CHAMBERS}

Iain Chambers teaches Cultural and Postcolonial Studies of the Mediterranean at the University of Naples, 'Orientale'. He is author of Mediterranean Crossings. The Politics of an Interrupted Modernity (2008), and Postcolonial Interruptions, Unauthorised Modernities (2017). 